\title{
CONCEITO DE SAÚDE — PREDICATIVOS E IMPLICAÇõES *
}

\author{
Ieda Barreira e Castro
}

\begin{tabular}{ll} 
& RBEn/01 \\
\hline
\end{tabular}

CASTRO, I. B. - Conceito de saúde-predicativos e implicaçōes. Rev. Bras. Enf.; DF, 31 : 275-280, 1978.

\section{SAÚDE, COMPONENTE DA FELICIDADE}

A eficácia do funcionamento do corpo e da mente e a capacidade de interação com seus semelhantes sempre foram considerados fatores capitais para a felicidade das pessoas. Mais recentemente o "bem-estar físico, mental e social" foi reconhecido igualmente como fator de relevância sócio-politica, "indispensávei à felicidade e à harmonia entre todos os povos". Assim, vemos que saúde e felicidade são dois conceitos indissociáveis e, além disso, que a saúde e a felicidade pessoais são indissociáveis da saúde e da felicidade coletivas.

CHAVES (1972) analisa o ser humano como um sistema orientado para objetivos, sendo o telos da espécie humana a felicidade. Entre seus componentes menciona a satisfação das necessidades de alimentação e abrigo, sexo, saúde, €ducação, previdência social, satisfação no trabalho, aceitação social, recreação e estética. Devemos considerar também 0 interrelacionamento entre esses diversos fatores, pois a problemática de saú- de se desenvolve em grande parte fora do seu próprio setor, em áreas relacionadas a outras necessidades do ser humano e não pode ser modificada por ações de saúde, isoladamente.

Não obstante ser a saúde reconhecida como um dos direitos do ser humano **, cada qual (pessoa ou povo) tem o nível de saúde que lhe é possivel obter, pois o fenômeno saúde não pode ser isolado do contexto em que ocorre.

A saúde de uma pessoa ou de uma população depende essencialmente da quantidade de bens e de serviços que podem ser postos ao seu dispor e de sua capacidade de utilizá-los. Portanto, "saúde é um bem que se compra". Do mesmo modo que saúde e produção de bens e de serviços são fatores reciprocamente determinantes, a relação doença e pobreza configura-se como um processo circular e cumulativo.

Entretanto, nem sempre o crescimento econômico é acompanhado de pro. gresso social. Na atual década, a situação tornou-se tão confusa que os Mi-

- Trabalho apresentado pela Presidente da Associaçāo Brasileira de Enfermagem no dia 16 de maio de 1978 a I Jornada de Enfermagem Médico-Cirúrgica promovida pela ABEn/BA.

* Art. XXV da Declaraçāo Universal dos Direitos Humanos- ONU (1948). 
CASTRO, I. B. - Conceito de saúde-predicativos e implicações. Rev. Bras. Enf.; DF, 31 : 275-280, 1978.

nistros de Saúde das Américas ** julgaram necessário lembrar que "a saúde é um produto intersetorial e depende do desenvolvimento global. As decisōes econômicas não devem perder de vista que a finalidade da economia é o homem e seu bem-estar, e que o homem não é unicamente um meio da economia senão o seu fim, seu destino e sua razão de ser".

\section{SAÚDE, EXPRESSÃO DA QUALIDADE DA VIDA}

O fenômeno saúde pode ser apreciado sob um aspecto quantitativo e outro qualitativo. A expressão numérica da probabilidade de duração da vida de uma pessoa ao nascer é um indicador quantitativo. Não obstante, o aspecto quantitativo é muitas vezes medido pela ausência do fenômeno saúde, isto é, pela morte. A curva de mortalidade proporcíonal, obtida pela determinação do percentual, em relação ao total de óbitos, dos óbitos verificados nos diversos grupos etários, é um exemplo disto.

$O$ aspecto qualitativo se expressa em termos de graus, sendo a doença o fenômeno que é geralmente quantificado; as taxas de morbidade são expressas em termos de incidência e de prevalência. Constata-se a necessidade de se estudar indicadores positivos da qualidade de saúde, conforme mencionado por CHAVES (1972) como o perfil (análise do Estado de saúde num dado momento), o gradiente (síntese do estado de saúde em um dado momento) e o biograma (evolução histórica do estado de saúde).

$\mathrm{Na}$ avaliação da qualidade de saúde individual ou coletiva, em uma série histórica, é importante distinguir saúde e doença quanto a estar e quanto a ser, isto é, diferenciar o estado ou nível habitual de desempenho e os momentos de crise. Nesta avaliação adquire especial relevância o primeiro aspecto, isto é, a saúde como um estilo de vida *, influindo diretamente na qualidade da própria vida.

Embora a importância da saúde seja indiscutível, não é fácil precisar na verdade do que se trata, visto ser este um conceito estritamente relativo. Visto resultar da interação do indivíduo com c meio, se usássemos um padrão fixo para comparação, e dependendo do momento da vida em que se surpreendesse - sujeito, poderíamos ter observaçōes bastante divergentes, em talvez pequeros espaços de tempo, dependendo dos desequilíbrios surpreendidos entre seu organismo e o eco-sistema. Por isto, falamos em processo * * saúde-enfermidade, o que indica sua característica dinâmica.

Ainda mais, as pessoas consideradas "sadias" em dado momento não seriam comparáveis entre si, pois o estado de saúde de diversos órgãos e de sua mente seriam bastante dessemelhantes. Vale lembrar que dificilmente encontrariamos pessoas em perfeito estado de saúde ou, ao contrário, totalmente desprovidas dela. A retirada de órgãos de pessoas mortas para transplantes evidencia isto.

Além disso, os próprios padrōes usados para a comparação variariam, de acordo com a comunidade que o elegesse, pois saúde é também um conceito cultural e o que seria considerado normal, satisfatório ou adequado em um grupo poderia ser percebido como anormal, insatisfatório ou inadequado por

* III Reuniāo Especial de Ministros de Saúde das Américas.

* Conceito expresso no título da 1.2 Etapa Curricular constante do Projeto Novas Metodologias, DAU/UFRJ - v. CARVALHO, V (1978).

* Processo-Continuaçāo de coisas, e sucessos, que se seguem umas às outras. MORAES SILVA (1813). 
CASTRO, I. B. - Conceito de saúde-predicativos e implicaçōes. Rev. Bras. Enf.; DF, 31 : 275-280, 1978.

outro, e isto tanto do ponto de vista físico, como mental ou social.

Apesar dessas dificuldades, CHAVES (1972) elaborou uma conceituação de saúde que parece atender à sua natureza relativista: "saúde é um estado em que $o$ indivíduo tem $o$ vigor físico para o desempenho das atividades normalmente esperadas dos individuos de sua idade, nāo apresenta alteraçōes na estrutura ou no funcionamento de seus subsistemas (órgāos e aparelhos), que causem dor ou desconforto ou possam ser origem de doença e mantém harmonia e equilíbrio em suas funçōes mentais suficientes para uma vida normal de relaçōes com seus semelhantes, dentro da cultura a que pertence.

\section{SAUDE E SERVIÇOS DE SAƯDE}

A melhor compreensāo do conceito de saúde determinou a integraçāo de atipidades ditas "preventivas" e "curativas" por todos os serviços de saúde.

A prestaçāo de serviços de saúde à populaçāo constitui o ponto vulnerável do esforço da sociedade por um melhor nível de saúde, visto que a ciência e a tecnologia dispōem atualmente, de elementos para solucionar a maioria dos problemas de saúde das populaçōes.

Algumas diretrizes influem favoravelmente na prestaçāo dos serviços de saúde, como o planejamento (dos investimentos, dos recursos humanos e das açōes de saúde) voltado para as necessidades globais da comunidade. $O$ escalonamento dos serviços em níveis de complexidade e de localizaçāo geográfica estratégica permite uma distribuição de serviços mais razoável, com o desenvolvimento de açōes básicas de saúde em toda a área. Do ponto de vista administrativo, a regionalizaçāo promove o descongestionamento dos órgāos centrais; encurta a distância entre o rível local e o órgāo coordenador, permitindo melhor comunicaçāo e super- 71sao; evita a duplicidade de serviços, adequando os diversos órgãos atuantes na regiāo e padronizando métodos e técnicas; concentra os serviços especializados em pontos estratégicos, de modo a que deles possa dispor o maior número possível de habitantes, e reduz os custos. Entretanto, um sistema regionalizado de saúde só funcionará a contento se houver uma efetiva coordenaçāo entre todas as instituiçōes de saúde da regiāo.

A prestaçāo de serviços ocorre em vários níveis, denominando-se assistência primária, secundária, terciária e assim por diante. Entende-se por assistência primária o conjunto de açðes de saúde, simples mas objetivas, que são postas ao alcance das comunidades, ao nível periférico do sistema de saúde. A maioria dos casos que demandam os serviços de saúde podem ser solucionados a esse nível. Quando necessário, é facilitado ao cliente 0 acesso a níveis mais complexos de assistência.

Por outro lado, a cada nível de assistência serão prestados serviços correspondentes a vários níveis de prevenção, partindo da promoçāo da saúde e prerenção específica (prevenção primária), passando pelo diagnóstico e tratamento precoces (prevençāo secundária), até a limitaçāo do dano e a reabilitaçāo (prevençāo terciária) (LEAVELL \& CLARR/ 1965).

Assim, tanto uma unidade sanitária, situada $\mathrm{n}_{\mathrm{a}}$ periferia do sistema (assistência primária), quanto um hospital com pessoal especializado e equipamento sofisticado (assistência terciária ou quaternária) desenvolvem atividades características dos diversos níveis de prevençāo.

\section{SAÚDE - ESFORÇO CONJUNTO E ORGANIZADO}

Qualquer que seja o padrāo adotado, quer seja considerado ou como fenômeno individual ou coletivo, a saúde re- 
CASTRO, I. B. - Conceito de saúde-predicativos e implicaçōes. Rev. Bras. Enf.; DF, 31 : 275-280, 1978.

sulta de um esforço conjunto e organizado de todos os setores da sociedade, já que interdepende de tantos fatores.

No Brasil, tal esforço tomou forma legal a partir de 1975 , com a criação do Sistema Nacional de Saúde *, integrado pelos Ministérios da Saúde, da Previdência, da Educação, do Interior e do Trabalho, pelas Secretarias correspondentes das unidades federadas e dos municípios e também pelas entidades particulares interessadas na saúde, sob a coordenação do Conselho de Desenvolvimento Social.

A criação de tal sistema possibilita ao Governo atender a um dos mais urgentes reclamos, qual seja o de extensão da cobertura às populações pelos serviços de saúde.

Além da tendência à universalização da previdência, para o que vêm contribuindo os convênios firmados com serviços de saúde de órgãos federais e estaduais, observam-se outras, da maior importância para $o$ atendimento desse problema e de grande repercussão nos programas de saúde, como a integração docente-assitencial, a participação da comunidade nos referidos programas e a ampliação do papel da enfermeira.

A integração docente-assistencial deve ser entendida como um processo de interação, entre estudantes, profissionais (de ensino e de serviço) e a sociedade, que tem como objetivo efetuar o ensino-aprendizagem em situações reais e produtivas, incorporando o trabalho à educação. Tem como características principais a responsabilidade conjunta (docente-serviço) pela do nível de saúde da população atendida e o engajamento permanente de professores e alunos nos programas de trabalho dos serviços.

Além de possibilitar a extensão da cobertura à população, existem outras vantagens, de cunho educacional, igualmente importantes: a vinculação do estudante à realidade sanitária regional e a aquisição de valores positivos quanto ao trabalho, ao trabalho em equipe, à sua responsabilidade quanto à saúde da comunidade, à sua formação e aperfeiçoamento, e à participação da comurildade nos programas de saúde; a confrontação com problemas reais motivam o aluno ao estudo, incentivam sua criatividade e favorecem a ruptura de sua dependência quanto ao professor.

A participação da comunidade, além de multiplicar as potencialidades dos serviços de saúde, pela utilização de mão-de-obra adicional, permite "feed back" permanente do impacto causado pelas ações de saúde na população e jermite a apropriação do conhecimento relacionado à saúde pela comunidade.

PIOVESAM (1968) lembra que para que possa haver efetiva participação da comunidade em programas de saúde é necessário a crença em certos princírios, bem como determinadas atitudes da equipe de saúde, que podem ser assim explicitadas: o homem é o centro de interesse e a tecnologia é posta a $s \in u$ serviço; as pessoas, as famílias e as comunidades têm o direito de autodeterminar-se frente aos seus problemas de saúde; cada cidadão tem o dever de contribuir para o bem comum e, portanto, para a saúde coletiva; a assistência prestada à comunidade inclui os aspectos físicos, mentais e sociais; a ocorrência das doenças tem explicação multicausal; os programas têm como objetivo, além da melhoria da saúde da população, a mudança de conduta (manifesta ou latente) das pessoas frente aos problemas de saúde pública; a equipe de planejamento considera os hábitos da população, suas opiniōes e sentimentos; as decisões e a execuçán

* Lei 6.229/75 que cria o Sistema Nacional de Saúde. Além do Presidente e dos ministros das áreas acima citadas, assinaram esta lei os ministros da Fazenda e do Planejamento. 
CASTRO, I. B. - Conceito de saúde-predicativos e implicaçōes. Rev. Bras. Enf.; DF, 31 : 275-280, 1978.

do programa são da responsabilidade conjunta da equipe de saúde e da população; a avaliação inclui a verificaç̃̃o dos resultados, em termos de mudança de comportamento e de motivos de não aceitação; as atividades educativas do programa e a investigação social são altamente valorizadas pelo equipe de saúde.

A ampliação do papel da enfermeira decorre da modificação de conceitos, causada pelo progresso científico e social, o qual, por sua vez, exige a revisão e a readaptação das profissões à sociecade. Tal situação configura um periodo de crise, que se resolve pela redefinição de funções.

O fenômeno é universal e motivou a seguinte declaração do Conselho Internacional de Enfermeiras ICN feita em maio de 1973, na cidade do México, durante o XV Congresso Quadrienal: “A luz das mudanças ocorridas nos dominios científicos e sociais, e tendo em vista as metas da política de saúde, no sentido de estender os serviços de saúde a toda a população, a enfermagem e outras profissōes da área da saúde necessitam adaptar e expandir seus papéis".

Quanto à cobertura às populaçōes, caracteriza-se essa ampliação pela prestação de assistência primária a pessoas, quer sejam consideradas sadias ou doentes, e pelo treinamento e supervisão de pessoal auxiliar para programas de interiorização das ações de saúde. Vale lembrar que a prevenção primária (promoção e proteção da saúde) está presente em todos os niveis de assistência.

Intimamente ligada a esses objetivos, está a orientação da clientela em assuntos de saúde, atividade na qual o serviço de enfermagem tem grande parcela de responsabilidade. No entanto, o ensino dos pacientes e de suas famílias, de modo geral, vem sendo desenvolvido discretamente, principalmente nos hospitais.

CASTRO (1975) evidenciou que a função educativa é inerente à prática da enfermagem, o que está bastante evidente na conceituação, já clássica, de HENDERSON (1962), do que seja a função peculiar da enfermeira, quando diz que a enfermeira substitui o paciente na execução das atividades "que ele realizaria por si mesmo, se tivesse a força, a vontade ou o conhecimento necessários" e que a ela cabe o dever de ajudá-lo " $a$ tornar-se independente - mais rápido possivel". Afirma a autora que ficam assim caracterizados: o ensino do auto-cuidado (para o presente e para o futuro) e a preparação do paciente para a iniciativa de buscar informação e ajuda para seus problemas de saúde" e continua dizendo: "O cuidado de enfermagem é uma atividade individualizada e global, que abrange os aspectos físicos, psicológicos e sociais da pessoa assistida. Portanto, a atenção dada à famílila do paciente é decorrência lógica da assistência de enfermagem a ele prestada, qualquer que seja o tipo de instituição de saúde de onde emane".

A mesma autora menciona ALCÂNTARA, VALLADA \& RIBEIRO (1955), que já comentavam a confusão existente, na época, entre o ensino de aspectos preventivos da medicina e da cnfermagem, com 0 ensino de saúde pública. Assinalavam o esforço de algumas escolas, para a integração dos aspectos sociais e de saúde em todas as disciplinas do currículo, de modo a associar os aspectos preventivos à assistência de enfermagem em todas as suas modalidades e não apenas à área da saúde pública. Lembra ainda que $A L-$

Obs.: os grifos sāo nossos. 
CASTRO, I. B. - Conceito de saúde-predicativos e implicaçōes. Rev. Bras. Enf.; DF, 31 : 275-280, 1978.

VIM (1960) constatava ..."basicamente não difere o papel da enfermeira hospitalar do da enfermeira de saúde pública"... e recomenda que, quando se trata da enfermeira hospitalar, como daquela que irá trabalhar em saúde pública, deve ser dada atenção especial aos aspectos de seu preparo, "que valorizem a saúde e os fatores sociais e ambientes que a afetam".

A citada autora conclui que: "A assistência de enfermagem visa ao indivíduo $\epsilon$ à familia e inclui aspectos tanto pre- ventivos quanto curativos, onde quer que se dê a assistência: hospital, unidade sanitária, domićillo ou outro local. Por isto, a assistência à familia, os cuidados preventivos e a assistência domiciliar sāo pontos comuns à enfermagem de saúde pública e à enfermagem hospitalar e nāo podem ser tomados como características da primeira. Podem talvez caracterizar uma boa enfermagem hospitalar, desenvolvida em um hospital integrado no programa geral de saúde da comunidade".

\section{BIBLIOGRAFIA}

ALCANTARA, G; VALLADA, M. L. \& RIBEIRO, C. M. Aspectos preventivos da enfermagem hospitalar. Rev. Bras. Enf. - Rio de Janeiro, 8 (3): 199206 set. 1955.

ALVIM, \& F. - A integraçāo dos aspectos sociais, preventivos e curativos para a formação de um conceito de saúde pública. Rev. Bras. Enf. - Río de Janeiro, 13 (1) : 127-137, março, 1960.

Carvalyo, Vilma e cob. - Um projeto de mudança curricular no ensino de enfermagem em nivel de graduação que favorece aos propósitos emergentes da prática profissional.

III Tema Oficial - CBEn, Belém, 1978.

CASTRO, IB - Aspectos criticos do desempenho de funçbes próprias da enfermeira na assistencia ao paciente naio hospitalizado. Dissertaçāo de Mestrado apresentada à Escola de Enfermagem Ans Neri - UFRJ, 1975.

CRAVES, Mário - Saúde e Sistemas FGV/ Univ. Braspla, 1972.

HIFNDERSON, Virginla - Principios básicos sobre cuidados de enfermagem - Rio de Janeiro, ICN/ABEn, 1962.
INTERNATIONAL COUNCIL OF NURSES (ICN) - Declaração sobre a ampliaçāo do papel de enfermeira - México, 1973.

LEAVILL \& CLARK - Preventive medicine for the doctor in his community. An epidemiologic approach, 3.a ed., New York Mc Graw Hill, 1965.

MORAES SILVA, Antonio de - Dicionário da Língua Portuguesa - Lisboa, 1813.

PIOVESAM - Ideologias de trabalho em saúde pública. In $D a$ necessidade das escolas de saride priblica elaborarem métodos simplificados de investigação social. Tese de doutoramento - USP/ 1968.

\section{REUNIAO ESPECIAL DE MINSTROS DE} SAUDE DAS AMRRICAS, 3. Santiago, 2-9 oct. 1972. Plan decenal de salud para las Americas. Informe final de la III Reunion Especial de Ministros de Salud de las Americas. Washington, D. C., OPS/OMS, 1973 (DOcumento oficial n. ${ }^{\circ} 118$ ). 